\title{
Design and Evaluation of e-Government Applications and Services (DEGAS'2009)
}

\author{
Marco Winckler ${ }^{1}$, Monique Noirhomme-Fraiture ${ }^{2}$, Dominique Scapin ${ }^{3}$, \\ Gaëlle Calvary ${ }^{4}$, and Audrey Serna ${ }^{4}$ \\ ${ }^{1}$ University Toulouse 3, Institute of Research in Informatics of Toulouse (IRIT) \\ 118 route de Narbonne, F-31062 Toulouse, France \\ winckler@irit.fr \\ ${ }^{2}$ Institut d'Informatique, Facultés Universitaires Notre-Dame de la Paix (FUNDP) \\ Rue Grandgagnage 21, B-5000 Namur, Belgium \\ mno@info. fundp.ac.be \\ http: / / www. info. fundp.ac.be/ mno/ \\ ${ }^{3}$ INRIA Paris - Rocquencourt Research Centre, Domaine de Voluceau-Rocquencourt, B.P. \\ 105, Le Chesnay 78153, France \\ Dominique. Scapinainria.fr \\ ${ }^{4}$ University Joseph Fourier, Laboratory of Informatics of Grenoble (LIG) \\ 385, rue de la Bibliothèque, BP 53, 38041 Grenoble, France \\ Gaelle.Calvary @imag.fr
}

\begin{abstract}
The main goal of this workshop is to bring researchers and practitioners together to explore the issues and challenges related to the development of usable and accessible user interfaces for e-Government applications using innovative Information and Communication Technology (ICT). This workshop is the second in a series of workshops organized at IFIP TC 13 Interact conference focused on User Interfaces for e-Government applications. The present edition addresses the emergence of ubiquitous platforms and the multiple access points to e-Government applications. In particular, we are concerned by case studies, theories, applications, and design and evaluation methods for ubiquitous eGovernment applications that are committed with the universal access for citizens. DEGAS 2009 is officially supported by the IFIP WG 13.3 on HCI and disability and the IFIP WG 13.2 on Methodologies for User-Centered Systems Design.
\end{abstract}

\section{Workshop Background}

The increasing use of the Web as a software platform together with the advance of technology has promoted the Web platform as a suitable alternative for delivering information and services to citizens. However, the adoption of services provided to citizens depends upon how such applications comply to the users needs. The development and implementation of e-government involves consideration of its effects including environmental, social, cultural, educational, consumer issues, among others. On one hand, e-Government software is mandated to follow very strict requirements in terms of evolving regulation, use of legacy technologies, confidentiality protection, and technical constraints related to the management. On the other hand, the design of 
e-Government applications must consider the impact on the diversity of users in terms of age, language skills, cultural diversity, literacy, and information technologies practice. Some major constraints underline the importance of investment on the User Interface (UI) design and evaluation of e-Government applications:

- The ever growing number of users of e-Government applications calls for a universal access to e-Government applications. Usability has become one of the major challenges for large adoption of many e-services provided to citizens, in particular those suffering from some kinds of disability or having some literacy barriers (e.g. illiterate users, immigrants).

- E-Government applications present several advantages for both front office users (e.g. citizens, associations, companies and so on) and back office people (e.g. government employees, administrative clerks) as they reduce costs of information transfer and treatment. Thus front office and back office users are two sides of the same coin. Whilst universal access should be provided to front office users, usability for back office users should not be neglected as some usability problems could cause errors and/or losses of data that might compromise the quality of the whole system.

- Public administration should ensure multiple access points to e-Government applications allowing home access via Internet broadband, computer-based kiosks, as well as mobile platforms. Nowadays the large variety of computing systems (e.g. low-weight desktop/notebook computers, cell phones, Personal Digital Assistants - PDA, smart phones) has created a milestone for costeffective development and fast delivery of multi-target interactive systems.

- Citizens are faced with a large set of e-services (e.g., tax declaration, documents requests such as passports, procedures involving health care insurance, etc) which are provided by different governmental agencies. The availability of such e-services generates lots of personal data. As a result, privacy issues as well as management concerns (e.g., sharing data among different applications, recovering personal information from different applications) emerge.

- Bad design can have huge impact not only on the adoption of user interface by users but also compromise the validity of democratic processes. So that, accessibility had become a mandatory requirement for any e-Government initiative.

\section{Scope and Objectives}

This workshop is intended for anyone (researchers and practitioners) who is concerned with the design and/or evaluation of accessible and/or usable UIs. This includes representatives from administrations, academia (e.g., lecturers in HCI), and policy-making organizations. We aim at triggering a discussion on the topics related to the design and evaluation of ubiquitous e-Government applications, requirements and constraints for the development of e-Government applications, user experience with e-Government services, user involvement into the development process, universal access, policies for implementing accessibility and usability culture into government agencies. Expected outcomes for this workshop include a review of trends and currently available solutions for the design and evaluation of e-Government UIs and a research agenda for further developments in the field. 